\title{
Microfluidic delivery of cutting enzymes for fragmentation of surface-adsorbed DNA molecules
}

3

4

5

\section{Julia Budassi ${ }^{1}$, NaHyun Cho ${ }^{1}$, Anthony Del Valle ${ }^{2}$, Jonathan Sokolov ${ }^{*}$ \\ ${ }^{1}$ Department of Materials Science and Chemical Engineering, Stony Brook University, Stony Brook, New York, United States of America}

${ }^{2}$ Department of Physics and Astronomy, Stony Brook University, Stony Brook, New York, United States of America

\section{${ }^{*}$ Corresponding author}

E-mail: jonathan.sokolov@stonybrook.edu 


\section{Abstract}

48 We describe a method for fragmenting, in-situ, surface-adsorbed and immobilized DNAs on

49 polymethylmethacrylate(PMMA)-coated silicon substrates using microfluidic delivery of the

50 cutting enzyme DNase I. Soft lithography is used to produce polydimethylsiloxane (PDMS)

51 gratings which form microfluidic channels for delivery of the enzyme. Bovine serum albumin

52 (BSA) is used to reduce DNase I adsorption to the walls of the microchannels and enable

53 diffusion of the cutting enzyme to a distance of $10 \mathrm{~mm}$. Due to the DNAs being immobilized, the

54 fragment order is maintained on the surface. Possible methods of preserving the order for 55 application to sequencing are discussed.

\section{Introduction}

Significant progress in DNA sequencing has occurred over the last fifteen years, with

63 lengths and contig size [1-3]. Despite this, highly accurate and complete genome analysis at a

64 reasonable cost and with rapid turnaround time such as would be desirable for personalized

65 medicine has not yet been achieved. Short-read technologies (up to several hundreds of bases)

66 are capable of generating Terabases of data but have difficulty in mapping structural variations

67 and regions with long repeats. The 'repeatome,' comprising roughly half of the genome, has a

68 role in gene expression and in disease and exhibits a relatively high rate of mutation [4].

69 Synthetic long-read techniques grafted onto the short-read platforms have provided improvement

70 over the original methods [5-10] and some longer-read platforms have also appeared [11-16].

71 Nonetheless, no currently available technique is able to generate reads of a single DNA molecule 
72 greater than a few tens of kilobases. Since the range of human chromosome sizes is 47-249

$73 \mathrm{Mbp}$, there is still a need to assemble relatively small sequenced fragments into contigs and any

74 simplification of the process can have a significant impact.

75 All current sequencing requires the fragmentation of long DNA molecules into kilobase-sized

76 pieces or smaller for analysis. Long-range positional order is lost for the currently-used methods.

77 The most widely-used techniques are fragmentation by mechanical means or enzymatic mean

78 [17]. The mechanical techniques include sonicaton, hydrodynamic shearing through orifices

79 (driven by centrifugation or use of a syringe pump), focused acoustic shearing (commercialized

80 by Covaris, Woburn, MA) and nebulization (DNA suspended in a shearing buffer which is

81 forced through an orifice by compressed air or nitrogen gas). The enzymatic fragmentation

82 methods are based on nicking enzymes, restriction enzymes or various transposons (such as

83 Illumina's Nextera system, which fragments and adds adapters in the same step, referred to as

84 'tagmentation'). NEB has developed a product using a mixture of enzymes called 'Fragmentase'

85 (New England Biolabs, Ipswich, MA). For all methods, to greater or lesser degree, there are

86 issues of damage to the fragments and sequence bias of breaks in GC-rich vs. AT-rich regions

87 [18].

88 It is clear that a method which preserves the sequential ordering of the fragments would be

89 highly beneficial in simplifying the assembly problem. Two groups have published papers using

90 localized cutting on surface-immobilized DNAs, one using atomic force microscopy to

91 mechanically cut the molecules [19-21] while the second group used an electrochemical method

92 to locally activate (with $\mathrm{Mg}^{+2}$ ions) enzymatic cutting [22]. This work, while highly interesting,

93 involves cutting single (or very few) molecules at a time and is difficult to scale up. Our group

94 has developed a method to use soft lithography stamps to allow cutting of significantly larger 
95 numbers of surface-immobilized DNAs in parallel [23]. In that work, DNAs are deposited onto

96 a substrate by withdrawing a polymethylmethacrylate (PMMA)-coated silicon wafer out of a

97 DNA solution, a technique that has been termed 'molecular combing [24-26]. This method and a

98 technique developed for optical mapping on surfaces [27], have been used to deposit DNAs of up

99 to megabase pair length on flat substrates [28]. The DNAs are stretched, aligned and

100 immobilized along the direction of sample withdrawal at densities that depend on solution

101 concentration, buffer $\mathrm{pH}$ [29-30] and surface type. A soft lithography stamp [31], in the form of

102 a polydimethylsiloxane (PDMS) grating produced from a silicon master (see Fig 1), is 'inked'

Fig 1. Schematic of stamping method for fragmenting surface-adsorbed. A PDMS stamp in the form of a grating is 'inked' with DNase I cuttting enzyme and is brought into contact with a surface on which DNA molecules have been deposited.

with a DNase 1 solution and placed in contact with the surface containing the stretched and

109 immobilized DNA molecules. The DNAs are cut at the contact points of the stamp, maintaining

110 (on the surface) positional order. In that work [23], the DNAs were removed, en masse, by

111 desorbing the DNA into buffer (NEBuffer 3.1, B7203S) at $75^{\circ} \mathrm{C}$ for 20 minutes or dissolving

112 the substrate PMMA and purifying by phenol extraction. The fragments were end-repaired and

113 sequenced using the PacBio platform (without amplification of the fragments in the case of

114 desorption). Though the positional order was lost in those experiments, the cutting method was

115 successfully demonstrated and some ideas for maintaining the order of the fragments were

116 suggested.

117 However, the inking method for delivering the DNase 1 enzymes is rather difficult to

118 implement and we have sought to develop a more controllable technique. In this paper, we report 
119 on microfluidic delivery of the enzyme through micron-sized channels using soft lithography

120 stamps. This technique is more reproducible and also lends itself to a variety of applications

121 such as ordered removal of fragments or in-situ sequencing on the surface [32-33]. Another

122 advantage of the method is that the application of the cutting enzyme is done from solution and

123 so should have less steric hindrance than when applying by stamping.

\section{Materials and methods}

\section{Sample preparation}

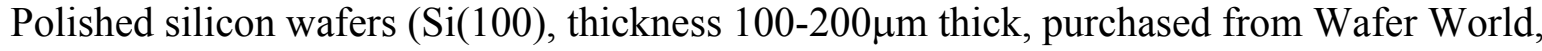

128 W. Palm Beach, FL) coated with PMMA layers, were used as

129 substrates for DNA adsorption. The wafers were scribed and cleaved to make $1 \mathrm{~cm} \times 2 \mathrm{~cm}$

130 samples. The wafers were cleaned using a modified Shiraki technique [34] as follows: (1) 10

131 minutes sonication in ethanol, (2) rinse in deionized (DI) water, (3) 15 minutes in boiling

132 solution of 3:1:1 ratio (by volume) of water: ammonium hydroxide (28-30\%) : hydrogen

133 peroxide (30\%), (3) DI rinse, (4) 15 minutes in boiling solution of 3:1:1 ratio of water : sulfuric

134 acid (98\%) : hydrogen peroxide (30\%), (5) DI rinse, (6) one minute in 9:1 solution of water :

135 hydrofluoric acid (49\%), (7) DI rinse. The resulting surfaces were hydrophobic.

136 A $15 \mathrm{mg} / \mathrm{ml}$ solution of PMMA (molecular weight 70K, Polymer Source, Inc., Canada) in

137 toluene was spun-cast (PWM32 spinner, Headway Research, Inc., Garland, Texas) onto the

138 silicon wafers at 2500 RPM for 30 seconds. The thickness of the resulting films was measured

139 using an ellipsometer (Auto El, Rudolph Research, Hackettstown, NJ) and was typically $70 \pm 8$

$140 \mathrm{~nm}$. Following spin-coating, the samples were annealed for $1-4$ hours at $130^{\circ} \mathrm{C}$ in an ion-pumped 
141 vacuum chamber (pressure $\leq 5 \times 10^{-7}$ Torr) to remove adsorbed ambient and any remaining

142 solvent.

143 DNA solutions for adsorption were produced in two steps. First, $200 \mu 1$ of a 50ng/ $\mu 1$ solution

144 (using Lambda DNA, New England Biolabs (NEB) N3011S), containing 1.5 $\mu$ l of the fluorescent

145 dye SyBr Gold (Invitrogen, S11494, Thermo Fisher Scientific, Waltham, MA) was prepared in a

146 buffer. The buffer was either a 6-12:50 mixture (by volume) of 0.1M sodium hydroxide : $0.02 \mathrm{M}$

147 2-(n-morpholino) ethanesulfonic acid (MES) or 1X NEB DNase I reaction buffer (NEB B0303S,

$1481 \mathrm{X}$ is $10 \mathrm{mM}$ Tris- $\mathrm{HCl}, 2.5 \mathrm{mM} \mathrm{MgCl}_{2}, 0.5 \mathrm{mM} \mathrm{CaCl}_{2}$ ). This solution was heated for one hour at

$14945^{\circ} \mathrm{C}$ to promote dye binding to the DNA. A further dilution in buffer by a factor of ten produced

$1502000 \mu \mathrm{l}$ of working solution at a DNA concentration of $5 \mu \mathrm{l} / \mathrm{mg}$.

151 DNA was adsorbed to the substrates by the technique called dynamic molecular combing

152 [26]. The DNA solution is placed in a teflon well and the sample, held vertically with teflon

153 tweezers, was lowered into the well and incubated for 30 seconds. The sample was then

154 withdrawn at a rate of $1-2 \mathrm{~mm} / \mathrm{s}$ using a computer-controlled stepping motor attached to a linear

155 drive stage (see Fig 2). The DNA molecules, preferentially attached by their ends, are stretched

156 linearly and immobilized on the surface as they are removed from the solution (see Fig 2).

Fig 2. Apparatus for dip-coating ('combing') DNA molecules onto a substrate by withdrawal from solution.

161

\section{Production of PDMS microfluidic channels}

163 The technique of soft lithography $[31,35]$ was used to produce PDMS elastomer gratings.

164 Silicon masters were made at the fabrication facilities of the Center for Functional Nanomaterials

165 at Brookhaven National Laboratory. Firstly, a Cr/sodalime mask (aBeam Technologies, 
Hayward, CA) was used to used to pattern a photoresist-coated Si wafer of diameter 4" by UV exposure using a Karl Suss MA6 Mask Aligner (Suss MicroTec SE, Garching, Germany). The photoresist layer spun-cast onto the silicon wafers, nominally $1.1 \mu \mathrm{m}$ thick, was a positive resist,

169 Shipley S1811 (Shipley Co., Marlborough, MA, USA). UV exposure was 5-40 seconds,

170 followed by $110^{\circ} \mathrm{C}$ bake for $30 \mathrm{~s}$. The photoresist pattern was developed for 20-50s using a 2:3

171 mixture of MF-312 developer (Microposit, Rohm and Haas, Marlborough, MA) : water. Etching

172 of the developed photoresist pattern to produce the silicon masters was done by reactive ion 173 etching (RIE, Trion Phantom III RIEtcher, Trion Technology, Clearwater, FL, USA). The gas

174 mixture was 40:10 $\mathrm{SF}_{6}: \mathrm{O}_{2}$ at a pressure of 100mTorr. Etching power was 100-150 W and 175 etching time was 300-700s. Leftover photoresist was dissolved in acetone. Optical microscopy 176 (Olympus BH2 BHT) and atomic force microscopy (AFM, Digital Nanoscope 3000) were used

177 to characterize the silicon patterns. Fig 3A shows an AFM image and Fig 3B the cross-section of 178 a typical sample. The depth of the channels in the grating pattern was typically $2-5 \mu \mathrm{m}$.

Fig 3, AFM image of silicon grating.

182 (A) AFM topographical image of a silicon grating used as a master mold for making PDMS stamps. (B) Height cross-section along the white line in (A).

187 Corning, Midland, MI, USA). A 10:1 mixture of elastomer and curing agent (by weight) was

188 mixed thoroughly and trapped bubbles were removed by placing the mixture in a vacuum

189 desiccator for one hour. The degassed PDMS was poured over the silicon mold to a thickness of

190 approximately $5 \mathrm{~mm}$. The silicon mold was precoated with a thin film (less than $10 \mathrm{~nm})$ of

191 PMMA, spun-cast from a 3mg/ml solution (molecular weight $70 \mathrm{~K}$ ). The purpose of the 
192 precoating was to reduce PDMS-silicon adhesion and facilitate removal of the PDMS layer. The

193 PMMA-coated molds could be reused multiple times. The PMMA could also be removed with

194 toluene and the wafers recoated for further use. The PDMS layers were cured at $60^{\circ} \mathrm{C}$ for 4 hours

195 and then peeled off the molds. A typical cross-section of the grating, exposed by cutting the mold

196 with a razor, is shown in the optical micrograph of Fig 4.

197

Fig 4. Optical Micrograph of a cross-section of a PDMS grating.

Microfluidic channels (approximately $4.5 \pm 0.1 \mu \mathrm{m} \times 3.7 \pm 0.3 \mu \mathrm{m} \times 12 \pm 2 \mathrm{~mm}$, width by height

by length, respectively) were made by placing the PDMS grating stamps in contact with the

210 DNase I (NEB B0303S, Ipswich, MA USA), is delivered through the channels, as described

211 below. The DNase I cuts the surface-immobilized DNAs along the channels while the PDMS

212 stamp protects the DNA between the channels from being cut. 


\section{Results and discussion} concentrations of DNase I and placed $3 \mu$ l drops onto PMMA-coated samples with adsorbed

221 DNA. The samples were heated at $40^{\circ} \mathrm{C}$ for 20 minutes, with the drops covered by mineral oil 222 (M5904, MilliporeSigma, Burlington, MA) to prevent evaporation. They were then imaged by 223 fluorescence microscopy to determine an effective enzyme concentration for cutting. The stock

224 DNase I solution of 2Units(U)/ $\mu$ l was diluted in DNase I Reaction Buffer to concentrations

$2250.024 \mathrm{U} / \mu \mathrm{l}, 0.048 \mathrm{U} / \mu \mathrm{l}$ and $0.095 \mathrm{U} / \mu \mathrm{l}$ (the recommended concentration for reactions in solution is 226 given by the manufacturer as $0.02 \mathrm{U} / \mu \mathrm{l})$. Effective digestion was found for both of the higher 227 concentrations, though somewhat more completely for the highest concentration. (see Fig 6). In

228 further experiments, the concentration of $0.095 \mathrm{U} / \mu \mathrm{l}$ was used unless noted otherwise. These 229 results are consistent with the work of Gueroui et al [36], who observed digestion of combed 230 DNA on a PMMA surface under similar conditions. (They also observed that for the restriction 231 endonucleases HindIII and DraI the solution-level biochemical activity was not observed. We

232 found the same result for PvuI.)

Fig 6. Fluorescence image of SyBr Gold labeled DNA.

235 Upper left area was covered with a solution containing 0.095U/ $\mu$ l of DNase I in NEB DNase I 236 Reaction Buffer and shows effective digestion of DNA in that region.

For the first set of cutting experiments, a PDMS stamp placed in contact with a DNA sample 240 had its reservoir filled up with $300 \mu$ l of the DNase I solution. To fill the long, narrow

241 microfluidic channels (micron-sized cross-section by mm lengths) with the solution can be done 242 in a number of ways - using capillary action (the PDMS surface needs to be made hydrophilic), 
243 applying vacuum at an open end away from the reservoir or applying pressure above the liquid in

244 the reservoir, for example. We have used a convenient method [37], termed by the authors the

245 'channel outgas technique.' In this method, pressure is lowered above the reservoir (or the entire

246 device is submerged in the filling liquid), causing air bubbles from the channels to escape

247 through the liquid due to the buoyancy effect and allowing the channels to be filled with solution

248 from the reservoir. The sample with stamp and reservoir was placed in a vacuum chamber (using

249 an Edwards diaphragm pump having a teflon-coated diaphragm to enable pumping of high vapor

250 pressure liquids) and the pressure was lowered to 20 Torr for 40 minutes. The sample, with

251 channels now filled with the enzyme solution, was removed from the vacuum chamber and

252 placed on a $40^{\circ} \mathrm{C}$ hotplate for 90 minutes to effect DNA digestion in the channels. The result was

253 that digestion only occurred close to inlet of the reservoir, to a distance of less than $0.1 \mathrm{~mm}$. This

254 raised a concern that perhaps the DNase I enzyme was damaged due to shearing forces exerted

255 during the filling [38]. Therefore, it was decided to fill the channels first with buffer as above

256 (20 Torr for 40 minutes) and then to add enzyme solution to the reservoir and allow penetration

257 into the channels by diffusion (at $40^{\circ} \mathrm{C}$ for 90 minutes) through the liquid. The resulted in

258 effective cutting of the DNA to a distance of $1.1 \pm 0.2 \mathrm{~mm}$ from the inlet (Fig 7).

Fig 7. Fluorescence image of fragmented DNA remaining after digestion by DNase I diffusing through microfluidic channels.

262 Distance from reservoir inlet is $1.1 \mathrm{~mm}$.

Following this modest improvement, we tried a series of similar experiments, lengthening the 
2675 hours all showed cutting up to a distance of approximately $1 \mathrm{~mm}$. A set of experiments varying

268 the concentration of DNase I was tried next, with concentrations of $0.195,0.295,0.395,0.495$

269 and $0.595 \mathrm{U} / \mu 1$ used (vacuum fill of buffer as above, followed by 2 hour $40^{\circ} \mathrm{C}$ heating/diffusion

270 step). No clear trend was discernible, though the best sample, for $0.495 \mathrm{U} / \mu 1$, had a cutting

271 distance of $1.8 \mathrm{~mm}$.

272 At this point, it occurred to us that enzyme adsorption to the walls of the channels might be

273 limiting the diffusion of the DNase I. Previous studies [39,40] have shown that proteins may be

274 adsorbed to PDMS and also that bovine serum albumin (BSA) may be used to block protein

275 adsorption [41]. Two experiments were conducted in which the vacuum filling of the channels

276 with buffer was followed by a heating/diffusion step of 1 hour at $40^{\circ} \mathrm{C}$ with the reservoir filled

277 with a solution containing both DNase I (at $0.096 \mathrm{U} / \mu \mathrm{l})$ and BSA (NEB B9000S) at $0.13 \mathrm{mg} / \mathrm{ml}$

278 or $0.40 \mathrm{mg} / \mathrm{ml}$. The lower BSA concentration had little effect on the cutting distance. However,

279 the higher concentration sample showed enzymatic cutting to a distance of $3.3 \mathrm{~mm}$.

280 Next, we decided to try to diffuse in the BSA separately from, and before, the cutting enzyme.

281 In addition, due to the sometimes excessive bubbling of the liquid in the reservoir during vacuum

282 filling (the boiling point of water at 20 Torr is $21.9^{\circ} \mathrm{C}$, quite close to typical room temperature),

283 the vacuum filling was done at 120 Torr for 40 minutes. The sample was also tilted at $45^{\circ}$ to the

284 horizontal to promote escape of gas bubbles from the channels. Following the vacuum filling,

285 BSA was added to the reservoir to a concentration of $0.40 \mathrm{mg} / \mathrm{ml}$ and left to incubate at $40^{\circ} \mathrm{C}$ for

2861 hour. (As a check on the diffusion rates of BSA, we ran tests using fluorescently-labeled FITC-

287 BSA (ThermoFisher Scientific, Waltham, MA), see Fig 8.) Afterwards, DNase I was added to

$2880.095 \mathrm{U} / \mu \mathrm{l}$ in the reservoir and incubated for 2 hours. With these changes, the effective cutting

289 distance was increased to $5.0 \pm 0.4 \mathrm{~mm}$. 
Fig 8. Measured diffusion distance of FITC-labeled BSA through micorfluidic channels versus diffusion time.

Further optimization was obtained by using the same steps but varying the BSA concentration up to $1.07 \mathrm{mg} / \mathrm{ml}$, varying BSA incubation time up to 3 hours and DNase I incubation time also up to 3 hours. This produced a significant improvement, with cutting distances of $10 \mathrm{~mm}$ consistently achieved. Fig 9 shows a sample with effective digestion for a sample with high

299 density of adsorbed DNA. concentrations fixed. The following streamlined protocol was found: filled with $150 \mu 1$ of DNase I Reaction Buffer.

312 (3) 60 minutes incubation with reservoir covered by parafilm to reduce evaporation.

313 (4) Addition of $7.5 \mu \mathrm{l}$ of DNase I stock to reservoir, making the concentration 0.09 Units/ $\mu 1$.

314 Follow with mixing by careful up-and-down pipetting.

315 (5) 1 hour of incubation at $40^{\circ} \mathrm{C}$ with reservoir covered by parafilm. 


\section{Conclusions}

318 We have demonstrated an effective and reproducible method for the fragmentation of surface-

319 adsorbed and immobilized DNAs using soft lithography and microfluidic delivery of

320 an anti-fouling coating (BSA) and the cutting enzyme (DNase I). This method also lends itself

321 to ordered microfluidic removal of the fragments for sequencing applications or in-situ

322 Next Generation Sequencing [33]. Removal of the fragments is complicated by the competing

323 requirements of having relatively strong DNA-surface interactions, to enable immobilization on

324 the surface, versus needing relatively weak interactions to allow desorption. One approach,

325 which we are currently exploring, is to use a substrate which exhibits a reversible solubility

326 switch from water-soluble to water-insoluble [42]. The immobilization is done in the water (and

327 DNA-compatible buffer)-insoluble state while desorption is done into a water-based buffer

328 which may be flowed through the channels. Alternatively, rather than use long microchannels, a

329 PDMS stamp with holes used to create separate chambers could be used for fragmenting and

330 amplifying/sequencing in-situ. Also, as noted above, steric hindrances can affect enzyme activity

331 and the use of microporous substrates $[43,44]$ can broaden the range of useable enzymes.

\section{Acknowledgments}

334 This research used resources of the Center for Functional Nanomaterials, which is a U.S.

335 DOE Office of Science Facility, at Brookhaven National Laboratory under Contract No. DE-

336 SC0012704. We thank Ke Zhu, Donald Liu, Alan Gan, Sara Goodwin and Adriana Pinkas-

337 Sarafova for assistance with the experiments and for discussions. 


\section{References}

1. Mardis, ER. Next-generation DNA sequencing methods. Annual Review of Genomics and Human Genetics. 2008; 9: 387-402.

2. Goodwin, S, McPherson, JD, McCombie, WR. Coming of age: ten years of Next-Generation Sequencing Technologies. Nature Reviews Genetics. 2016; 17: 333351.

3. Giani, AM, Gallo, GR, Gianfranceschi, L, Formenti, G. Long walk to genomics: History and current approaches to genome sequencing and assembly. Computational and Structural Biotechnology Journal. 2020; 18: 9-19.

4. Hannan, AJ. Tandem repeats mediating genetic plasticity in health and disease. Nature Review Genetics. 2018; 19(5): 286-298.

5. Kitzman, JO, Mackenzie, AP, Adey, A, Hiatt, JB, Patwardhan, RP, Sudmant, $\mathrm{PH}$, et al. Haplotype-resolved genome sequencing of a Gujarati Indian individual. Nature Biotechnology. 2011; 29: 59-63.

6. Peters, BA, Kermani, BG, Sparks, AB, Alferov, O, Hong, P, Alexeev, A, et al. Accurate whole-genome sequencing and haplotyping from 10 to 20 human cells. Nature. 2012; 487: 190-195.

7. Amini, S, Pushkarev, D, Christiansen, L, Kostem, E, Royce, T, et al. Haplotyperesolved whole-genome sequencing by contiguity-preserving transposition and combinatorial indexing. indexing indexing. Nature Genetics. 2014; 46: 1343-1349.

8. Zheng, GX, Lau, BT, Schnall-Levin, M, Jarosz, M, Bell, JM, et al. Haplotyping germline and cancer genomes with high-throughput linked-read sequencing. Nature Biotechnology. 2016; 34: 303-311.

9. Bruinsma, S, Burgess, J, Schlingman, D, et al. Bead-linked transposomes enable a normalization-free workflow for NGS library preparation. BMC Genomics. 2018; 19: Article 722.

10. Chen, H, Yao, J, Fu, Y, Pang, Y, Wang, J, Huang, Y. Tagmentation on microbeads: restore long-range DNA sequence information using Next Generation Sequencing with library prepared by surface-immobilized transposomes. ACS Applied Materials and Interfaces. 2018; 10: 11539-11545.

11. Eid, J, Fehr, A, Gray, J, Luong, K, Lyle, J, et al. Real-time DNA sequencing from single polymerase molecules. Science. 2009; 323(5910): 133-138.

12. Deamer, D, Akeson, M, Branton, D. Three decades of nanopore sequencing. Nature Biotechnology. 2016; 34: 518-524. 
13. Gordon, D, Huddleston, J, Chaisson, MJ, Hill, CM, Kronenberg, ZN, Munson, KM, Malig, M, Raja, A, Fiddes, I, Hillier, LW, Dunn, C, Baker, C, Armstrong, J, Diekhans, M, Paten, B, Shendure, J, Wilson, RK, Haussler, D, Chin, CS, Eichler, EE. Longread sequence assembly of the gorilla genome. Science. 2016; 352(6281): aae0344-1 to -7.

14. Mantere, T, Kersten, S, Hoischen, A. Long-read sequencing emerging in medical genetics. Frontiers in Genetics. 2019; 10: Article 426.

15. Shafin, K, Pesout, T, Lorig-Roach, R, et al. Nanopore sequencing and the Shasta toolkit enable efficient de novo assembly of eleven human genomes. Nature Biotechnology. 2020; https://doi.org/10.1038/s41587-020-0503-6.

16. Amarasinghe, SL, Su, S, Dong, X, Zappia, L, Ritchie, ME, Gouil, Q. Opportunities and challenges in long-read sequencing data analysis. Genome Biology. 2020; 21(1): 1-16.

17. Knierim, E, Luckel, B, Schwarzl, J. M, Schuelke, M, Seelow, D. Systematic comparison of three methods for fragmentation of long-range PCR products for Next Generation Sequencingl. PloS ONE. 2011; 6(11): e28240.

18. Poptsova, M, Il'icheva, I, Nechipurenko, D, et al. Non-random DNA fragmentation in nextgeneration sequencing. Science Reports. 2015; 4: 4532 https://doi.org/10.1038/srep04532.

19. Kurosawa, O, Okabe, K, Washizu, M. DNA analysis based on physical manipulation Proceedings of the 13th Annual International Conference on Micro Electro Mechanical Systems (MEMS 2000) pp. 311-316.

20. Yamamoto, T, Kurosawa, O, Kabata, H, Shimamoto, N, Washizu, M. Molecular surgery of DNA based on electrostatic micromanipulation. IEEE Transactions on Industry Applications. 2000; 36(4): 1010-107.

21. Kurosawa, O, Washizu, M. Dissection, acquisition and amplification of targeted position of electrostatically stretched DNA. Journal of Electrostatics. 2007; 65: 423-430.

22. Mizuno, A, Katsura, S. DNA immobilized on glass, localized Mg ions activated EcoRI restriction enzyme manipulation of a large DNA molecule using the phase transition. Journal of Biological Physics. 2002; 28: 587-603.

23. Cho, N, Goodwin, S, Budassi, J, Zhu, K, McCombie, WR, Sokolov, J. Fragmentation of surface adsorbed and aligned DNA molecules using soft lithography for Next-Generation Sequencing. Journal of Biosensors \& Bioelectronics. 2017; 8(3): DOI: 10.4172/21556210.1000247.

24. Bensimon, A, Simon, A, Chiffaudel, A, Croquette, V, Heslot, F, Bensimon, D. Alignment and sensitive detection of DNA by a moving interface. Science. 1994; 265(5181): 2096-8. 
25. Bensimon, D, Simon, AJ, Croquette, V, Bensimon, A. Stretching DNA with a receding meniscus: experiments and models. Physical Review Letters. 1995; 74(23): 4754-4757.

26. Michalet, X, Ekong, R, Fougerousse, F, Rousseaux, S, Schurra, C, Hornigold, N, van Slegtenhorst, M, Wolfe, J, Povey, S, Beckmann, JS, Bensimon, A. Dynamic molecular combing: stretching the whole human genome for high-resolution studies. Science. 1997; 277(5331): 1518-1523.

27. Schwartz, DC, Li, X, Hernandez, LI, Ramnarain, SP, Huff, EJ, Wang, Y-K. Ordered restriction maps of Saccharomyces cerevisiae chromosomes constructed by optical mapping. Science. 1993; 262(5130); 110-114.

28. Kaykov A, Taillefumier T, Bensimon A, Nurse P. Molecular combing of single DNA molecules on the 10 megabase scale. Scientific Reports. 2016; 6:19636: DOI:10.1038/srep19636.

29. Allemand, JF, Bensimon, D, Jullien, L, Bensimon, A, Croquette, V. pH-dependent specific binding and combing of DNA. Biophysical Journal. 1997; 73: 2064-2070.

30. Benke, A, Mertig, M, Pompe, W. Ph- and salt-dependent molecular combing of DNA: experiments and phenomelogical model. Nanotechnology. 2010; 22(3): doi: 10.1088/09574484/22/3/035304.

31. Xia, Y, Whitesides, GM. Soft lithography. Angewandte Chemie International Edition. 1998; 37: 550-575.

32. Schwartz, J, Lee, C, Hiatt, JB, et al. Capturing native long-range contiguity by in-situ library construction and optical sequencing. Proceedings of the National Academy of Science. 2012; 109(46): 18749-18754.

33. Feng, K, Costa, J, Edwards, JS. Next-generation sequencing library construction on a surface. BMC Genomics. 2018; 19:416: https://doi/10.1186/s12864-018-4794-4.

34. Okumura, H, Akane, T, Tsubo, Y, Matsumoto, S. Comparison of conventional surface cleaning methods for Si molecular beam epitaxy. Journal of the Electrochemical Society. 1997; 144: 3765-3768.

35. Whitesides, GM, Ostuni, E, Takayama, S, Jiang, X, Ingber, DE. Soft lithography in biology and biochemistry. Annual Review of Biomedical Engineering. 2001; 3: 335373.

36. Gueroui, Z, Place, C, Freyssingeas, E, Berge, B. Observation by fluorescence microscopy of transcription on single combed DNA. Proceedings of the National Academy of 
Sciences. 2002; 99(9): 6005-6010.

37. Monahan, J, Gewirth, AA, Nuzzo, RA. Method for filling complex polymeric microfluidic devices and arrays. Analytical Chemistry. 2001; 73(13): 3193-3197.

38. Clarkson, JR, Cui, ZF, Darton, RC. Protein denaturation in foam. Journal of Colloid and Interface Science. 1999; 215(2): 333-338.

39. James, CD, Davis, RC. Kam, L, Craighead, HG, Isaacson, M, Turner, JN, Shain, W. Patterned protein layers on solid substrates by thin stamp microcontact printing. Langmuir. 1998; 14(4): 741-744.

40. Bernard, A, Delamarche, E, Schmid, H, Michel, B, Bosshard, HR, Biebuyck, H. Printing patterns of proteins. Langmuir. 1998; 14(9): 2225-2229.

41. Ostuni, E, Chen, CS, Ingber, DE, Whitesides, GM. Selective deposition of proteins and cells in arrays of microwells. Langmuir. 2001; 17: 2828-2834.

42. Linder, V, Gates, BD, Ryan, D, Parviz, BA, Whitesides, GM. Water-soluble sacrificial layers for surface micromachining. Small. 2005; 1(7): 730-736.

43. Fuke A, Suzuki, T, Nakama, K, Kabata, H, Kotera, H. High-throughput gene analysis using suspending DNA fibers (SDFs) on a micro glass-phonorecord. Twelfth International Conference on Miniaturized Systems for Chemistry and Life Sciences. October 12 - 16, 2008; San Diego, California, USA, 1519-1521.

44. Trigo-Lopez, M, Vallejos, S, Reglero Ruiz, JA, Ramos, C, Beltran, S, García, FC, García, JM. Fabrication of microporous PMMA using ionic liquids: An improved route to classical ScCO2 foaming process. Polymer. 2019; 183: 121867. 


\section{PDMS Soft Lithography Grating}

Enzyme

DNA

Substrate 


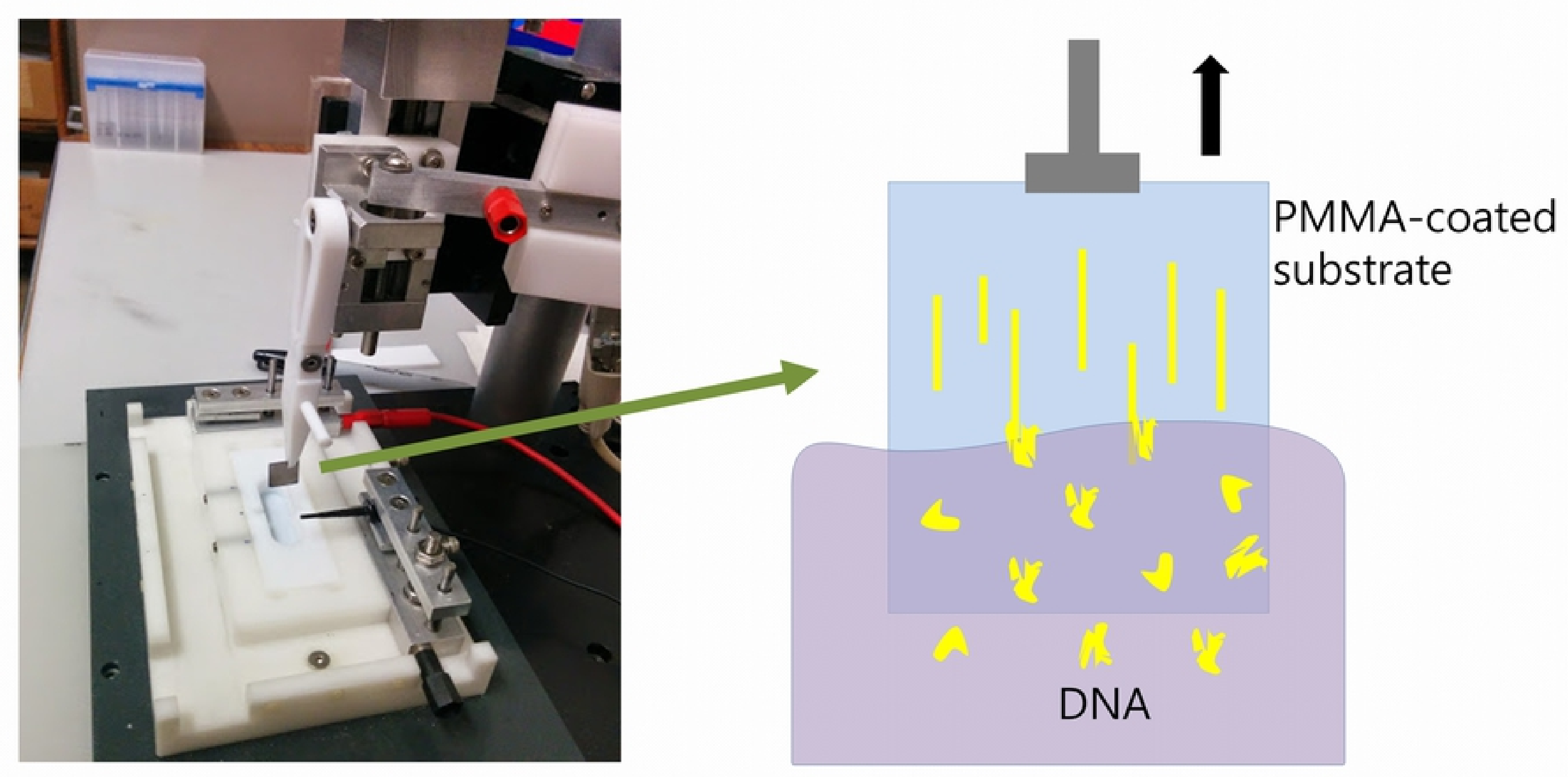




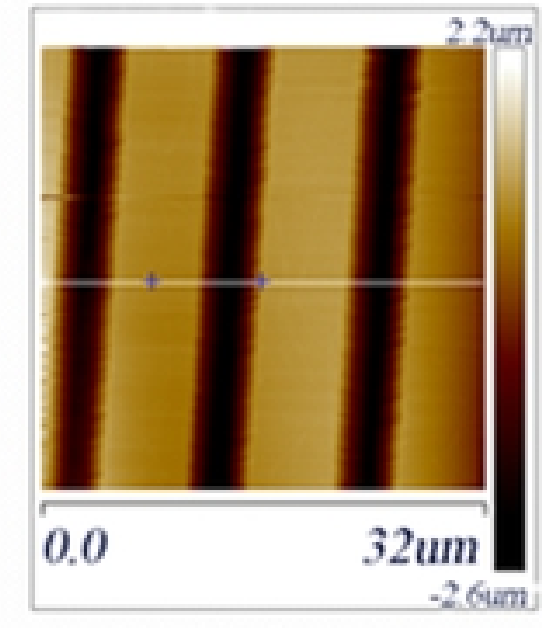

A

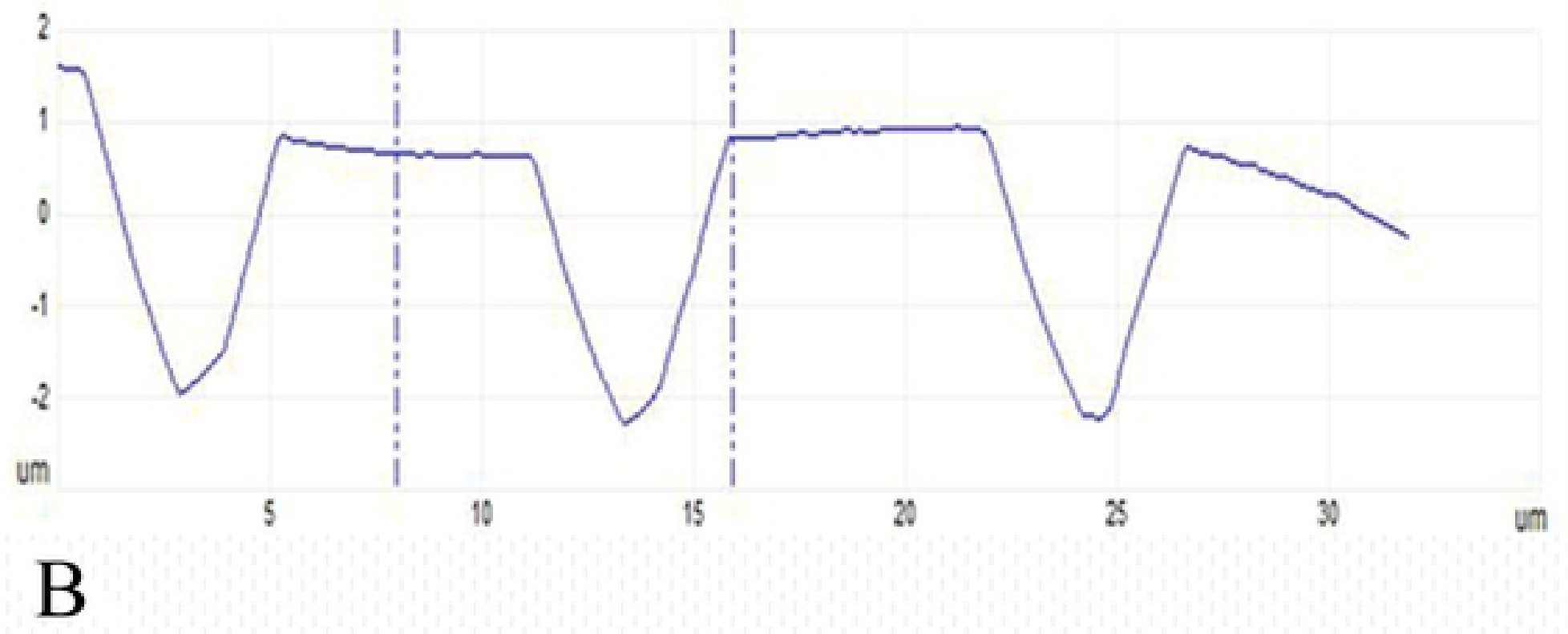


ararararararar

$\overline{10 \mu \mathrm{m}}$ 


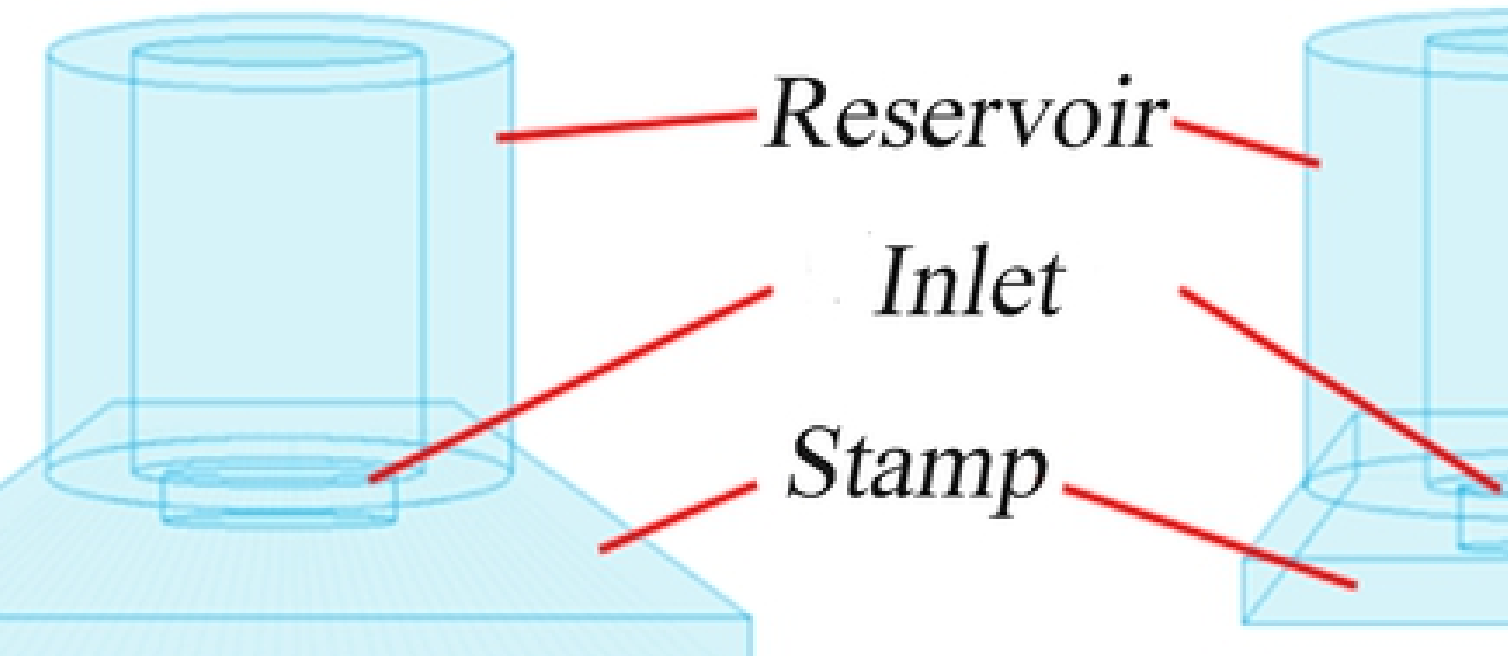



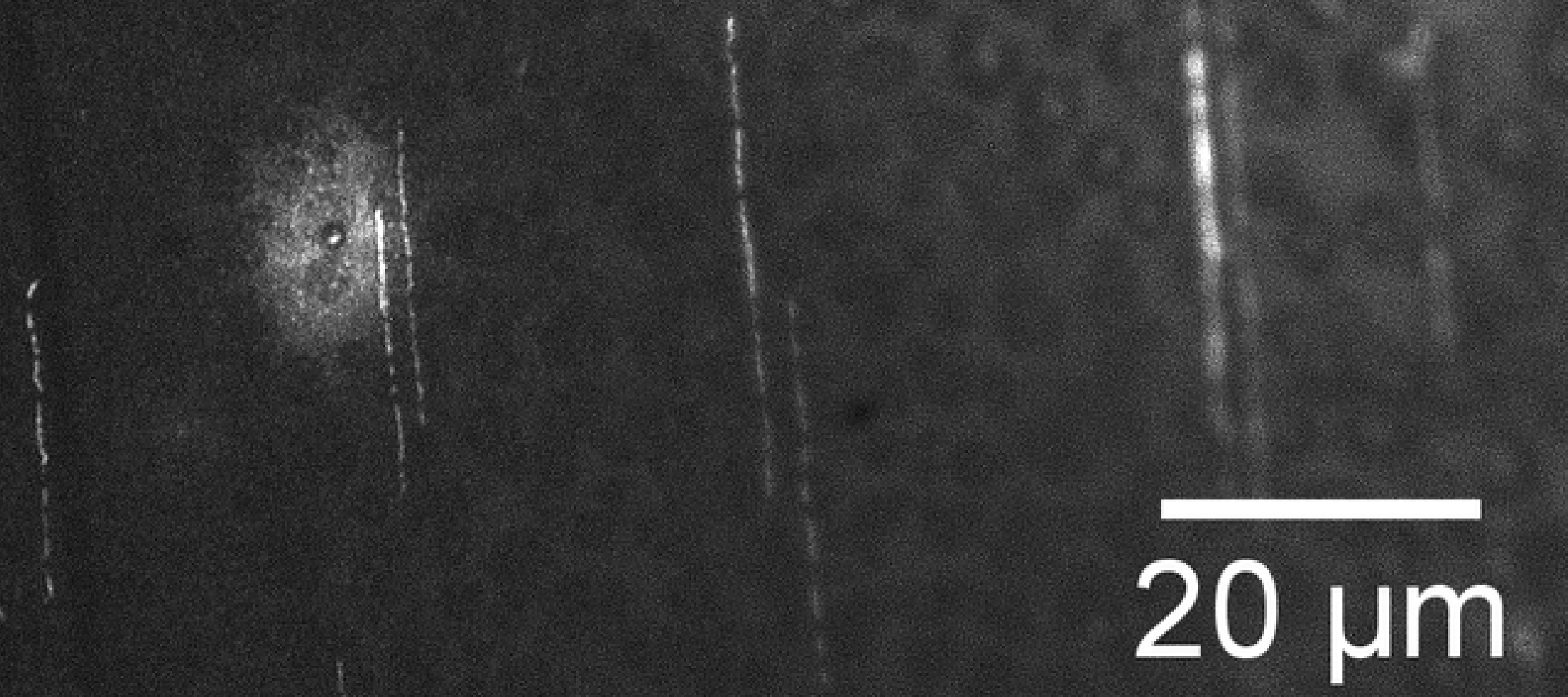


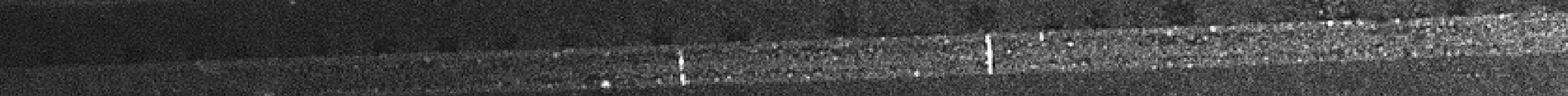

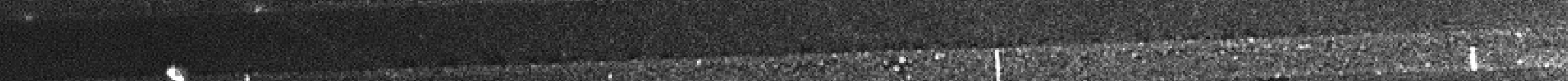

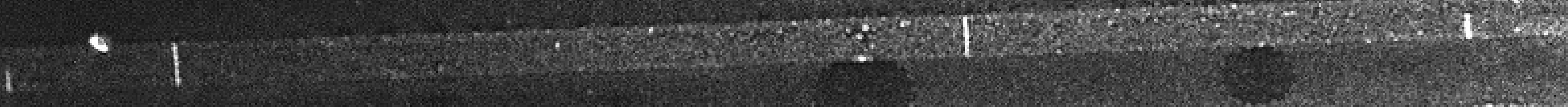

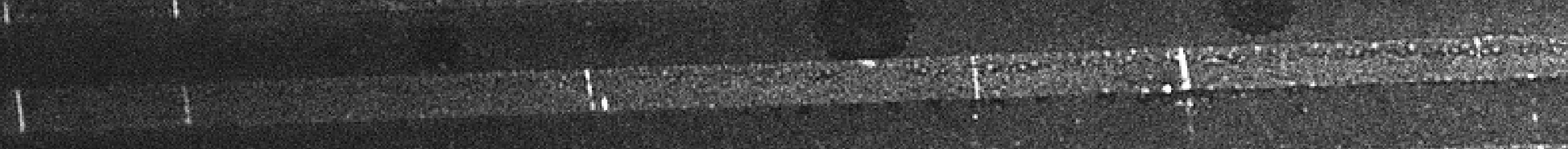

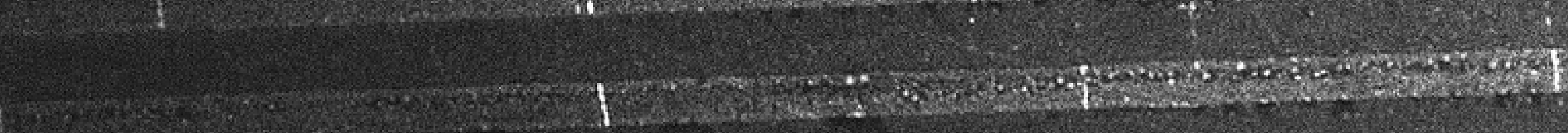

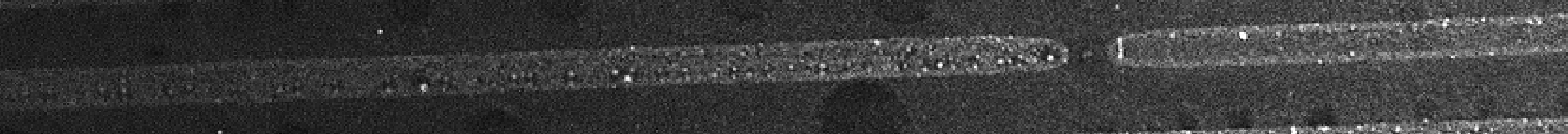

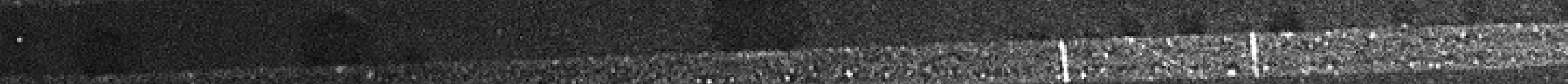
1. Whe

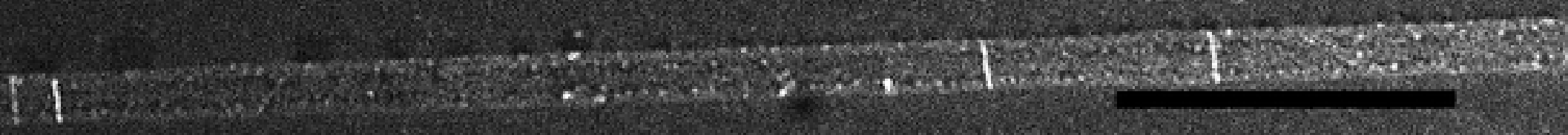
I. $20 \% \mathrm{~m}$ 


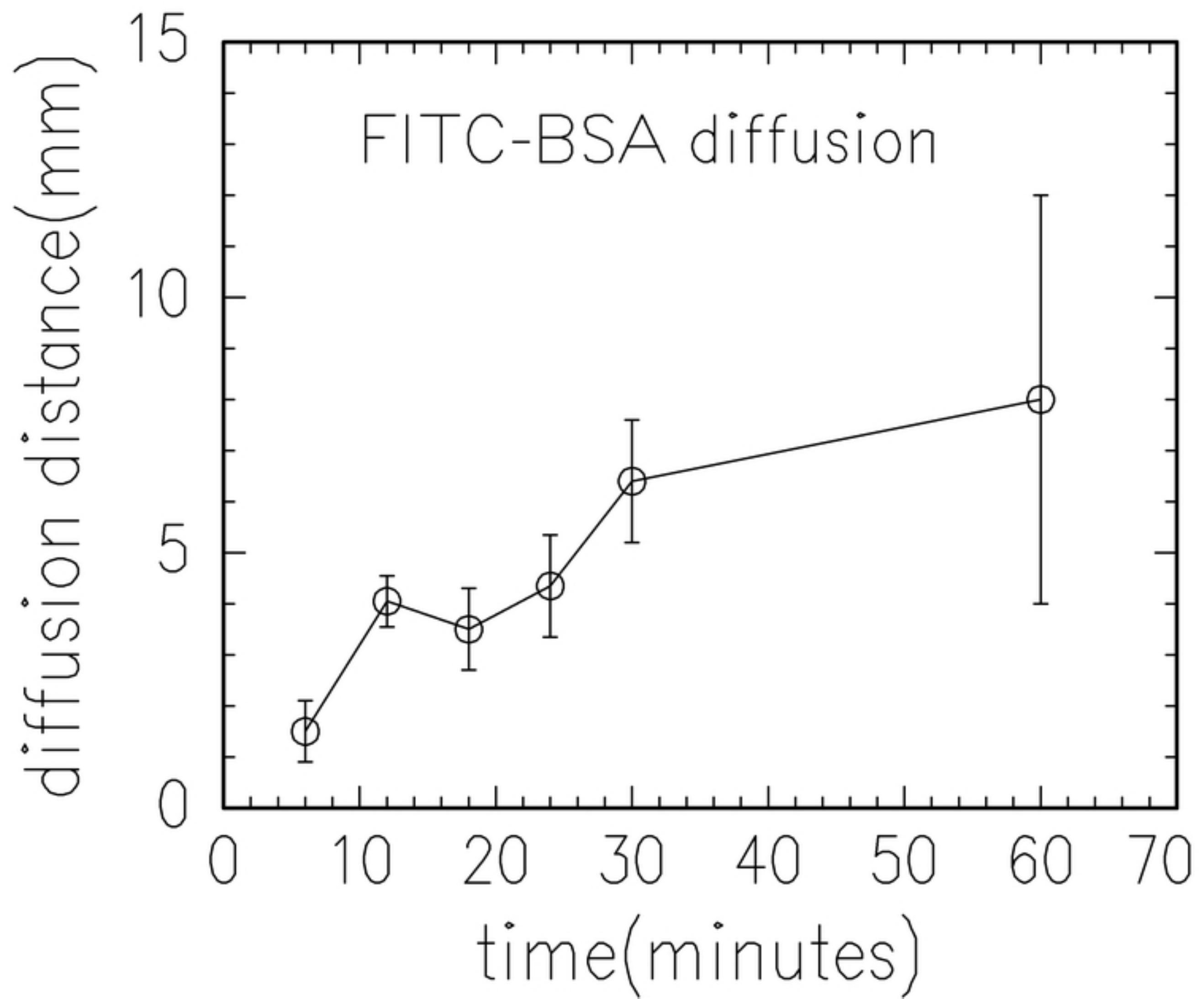


